\title{
Peer Review and Responsibility in/as/for/to Practice
}

\author{
Stuart G. Finder and Mark J. Bliton
}

\section{A Beginning Thought}

"I beg of you, Doctor, please don't let Dr. Moore see my mother again. My sisters and I do not want him talking with us anymore."

These opening lines of "The Zadeh Scenario" (Finder 2018: 21) foretell, in certain ways, many if not most of the core questions and themes that emerge in the ensuing layers of peer review and commentary that constitute Parts Two, Three, and Four of this volume: What is the appropriate role (and expectations and goals) of clinical ethics consultation? What are the proper goods and practices associated with actually "doing" clinical ethics consultation - and hence serving as a clinical ethics consultant? More importantly - certainly for the sake of this book but also for the field of clinical ethics if it is to promote and support critical engagement among practitioners - what is the best way to capture this "doing" such that peers might be able to provide not merely critical analysis but helpful feedback and guidance? And underneath all three of these questions is yet a more basic and crucial question: what is the most appropriate frame by which we who perform clinical ethics consultation can share with and learn from each other about our performances as clinical ethics consultants - and engage in such sharing and learning as both individuals and as a field?

The opening lines of "The Zadeh Scenario" also betray; while these lines serve as the beginning of Finder's narrative, they are not, as the reader comes to learn, the beginning of Finder's involvement with Mrs. Hamadani and her family: according

\footnotetext{
S. G. Finder $(\bowtie)$

Center for Healthcare Ethics, Cedars-Sinai Medical Center, Los Angeles, CA, USA

e-mail: Stuart.Finder@cshs.org
}

\section{J. Bliton}

Medical Bioethics, Kaiser Permanente Los Angeles Medical Center, Los Angeles, CA, USA

e-mail: Mark.J.Bliton@kp.org 
to the story Finder tells, there are at least two preceding moments in time when he encountered this patient and family. First, it was in the elevator, just moments before he had his initial brief conversation with Samir Zadeh, that Finder first directly encountered members of Mrs. Hamadani's family, albeit in the typical (at least in North American cultural contexts) non-engaged style of elevator etiquette, i.e., awareness of an other's presence, but beyond a possible socially-accepted statement, such as "what floor?," no apparent (according to the narrative) acknowledgement or interaction. More remotely, as the reader also learns - and as Finder remembers upon reflection while in the midst of his initial conversation with $\mathrm{Mr}$. Zadeh - he was familiar with Mrs. Hamadani and her family from prior review of "cases" which Finder and his colleagues routinely do as part of the normal functioning of the Clinical Ethics Consultation Service for which, the reader is told, Finder serves as the clinical chief and director.

But little else is provided about both of these encounters; the reader is not told, for instance, what Finder actually did in the elevator besides the fact that he, Samir, and Nadira (one of Mrs. Hamadani's daughters) "rode down to the bottom floor in silence" (Finder 2018: 21). Since this is the start of Finder's engagement with this family, the reader may wonder, did Finder look at them once he was in the elevator? If he did, for how long and in what ways? Did Samir and Nadira look at him? And were there any moments when Finder and Mrs. Hamadani's children noticed each other looking at each other (if in fact each did look at the other)? Or was Finder oblivious of Samir and Nadira beyond his initial noticing that they had been talking as he walked into the elevator but then ceased to talk once he was fully entered; after that, did he look at nothing in particular as the doors closed and the elevator gently glided down to the main floor? If this was the case, then the fact of what Samir and Nadira did or did not do is not something that Finder could report about, so perhaps this is the rationale for the lack of detail. The "encounter" in the elevator might have actually been less an encounter and more a mere accidental sharing of the space of an elevator moving from floor to floor.

On the other hand, given the typical experience of actually being within a confined space such as an elevator with other people, readers may wonder if Finder could have been fully oblivious; could he truly have not noticed such possible sensory elements as the scent of aftershave or perfume, or perhaps lingering food smells or even body odor? And what about where each stood in the elevator, how many floors it was until they reached the ground floor, and how far in front of Finder were Samir and Nadira as they, like him, walked through the lobby and out onto the plaza in front of the hospital's entrance? And did these children of Mrs. Hamadani engage in any conversation as they walked ahead of Finder, hushed murmurings that he might have slightly overheard? Or did they maintain their silence from the elevator even there in the foyer and out into the plaza?

Ordinary, everyday experiences of being in elevators or walking behind people while in public spaces often includes noticing such things; talking explicitly about them, however, is rare, possibly odd. To draw attention to them, after all, often infers evaluation - why else talk about what is otherwise left unsaid unless to suggest they 
are worth noting? Indeed, even here, in the above paragraph, with the mention of the possibility of noticing the scent of lingering food smells or body odor there is a risk of implying an evaluation since body odor in particular is rarely mentioned in ordinary, everyday interactions, including interactions that are part of clinical ethics consultation.

In "The Zadeh Scenario," there is no mention of any of these kinds of details that may have been present during Finder's encounter with Samir Zadeh. If the presence of details is typically taken to infer some sort of significance, is the lack of mention similarly significant, worth noting, worthy of attention? What this question elicits is what was discussed in the Introduction, namely, that determining the relevance and meaningfulness of the details of ordinary, everyday experiences requires a shift in attention, a different kind of "noticing" whereby focus is directed towards how, so to speak, thing are "lively" in the actual circumstances of their occurrence. In this light, think about what is presented in "The Zadeh Scenario," for example, when Samir begins that initial conversation with Finder. How striking is that encounter: Samir, whom Finder has not met, merely briefly encountered in the elevator, calls to Finder and then they are face-to-face, and Finder is called out - "I [see] on your name badge that you are the Director of Ethics and so I was thinking..." (Finder $2018,22)$. This is a confrontation, not merely a conversation. With Samir's calling out to, and calling out, Finder, Finder does not know what this is about nor how it is going to go. And so, almost immediately, even as Samir finishes his sentence, Finder must pay attention in a manner that will help him assess how best to be able to respond to whatever has prompted this "calling out." The elements of such an encounter, and the assessment that unfolds, thus begin to become layered. There is, for example, the ride down the elevator and previously unnoticed pre-judgments Finder may have made but which may now emerge as significant in terms of how Finder responds. There is, in other words, a shift in attention and awareness as Finder begins to try and understand, and learn, from why Samir has stopped and confronted him. But, as the reader knows and we have acknowledged here, Finder mentions nothing about any of these potentially influential matters in his narrative as he recollects that crucial first encounter on the plaza. Is this indicative of a failing, an act of irresponsibility, a deviousness on Finder's part? Or does it reflect the challenge of describing the nuances and moral relevance of such experiences in a way that is both faithful to what transpired then and to what will come to occur later on? While "The Zadeh Scenario" offers no answers, what it does offer is that, mentioned or not, the moment of confrontation between Samir and Finder on the plaza establishes a horizon between that moment, as a moment of "here and now," and whatever is to come later on.

In a similar way, readers might also note that although the Scenario does report that Finder recalled his colleague, Steve Moore, telling him about Mrs. Hamadani's situation at some points in the past, beyond the sketch of that reflection - which, it also could be noted, occurs in the midst of Mr. Zadeh telling Finder his story (should the reader be worried that Finder became distracted by his own thoughts when he should have been listening attentively to Mr. Zadeh?) - the Scenario provides the reader very little information about the character and content of those conversations 
Finder had with Moore. But surely those exchanges, as considerations about what was going on with Mrs. Hamadani and with her children that Moore encountered and reported, they played some role in preparing Finder (upon his recognition that this was that family) to not merely respond as he did but to interpret what he was doing, what they were doing, and what needed to be done going forward - all practical elements associated with judgment within clinical ethics. And yet, here too Finder offers no glimpse into these matters (nor do any of our contributors note their absence as potentially significant). And so a pertinent question might be, should Finder have told us more about this dimension of his experience?

For that matter, the readers of "The Zadeh Scenario" (be they the contributors to this book or you who now are reading this chapter, presumably after having also read the Scenario and the subsequent responses and reflections) are also not told what Finder and Moore (were there other colleagues involved as well?) discussed when Mrs. Hamadani's situation served as an example in one of the Clinical Ethics Consultation Service Reviews that is mentioned nor what had been the response to the fact, as duly referenced in "The Zadeh Scenario," that "no one [had been] willing to take the lead and more officially state, in Mrs. Hamadani's medical record or at a family conference, that continued treatment would not be appropriate, should not be pursued" (Finder 2018: 23).

All of the above is, in fact, another example of the layering and shifting of focus that is bound up with the unfurling of meaning in actual moments of engagement and interaction with others. Likewise, within the actual experience of colleagues talking about a particular clinical ethics situation, there are many details provided, some that may, at the moment of their delivery, seem to be relevant but turn out not to be given whatever subsequently happens as the consultation unfolds in the context of its actual circumstances. In fact, other details, minor at the initial time of their occurrence, come to be significant later on. And there are yet additional details, glanced or misremembered initially, that develop meaning and significance in the context of further details and events that unfold and emerge at yet still later moments. All of which is to say, clinical ethics practice, as clinical, is dynamic, unfolding, sometimes full of surprise, always experienced in real time, and otherwise engaging. Such is the nature of clinical ethics consultation.

"The Zadeh Scenario" does not provide a comprehensive articulation of any of these types and kinds of detail beyond the few lines about there being an encounter in the elevator and the unfurling of Finder's own recollection which interrupts Mr. Zadeh's relating his concerns to Finder at the very beginning of the narrative. As a starting point, then, for critical responses to" The Zadeh Scenario," it must be explicitly noted that there is a difference between talking about these details and layering in the actual circumstances of a specific ethics consultation and talking about them as an example of the practice of clinical ethics consultation - or even more, as an example submitted for evaluation of one's practice of ethics consultation. Understanding why distinguishing all of these is necessary turns out to be directly relevant to establishing a more accurate appreciation about how to evaluate Finder and "The Zadeh Scenario" - and is a significant step toward providing addi- 
tional insight into how to evaluate both clinical ethics practice and the written reports or narratives that attempt to accurately describe such practice in general.

In the case of "The Zadeh Scenario," one possible reason for its not providing all of these potential details and relevant layers is something else we discussed in the Introduction to this book: the Zadeh narrative is a fragment, and as such it should not be understood nor read as a total and complete documentation of everything that Finder thought and did over the course of the 3 years since Mrs. Hamadani's situation first appeared on the Clinical Ethics Consultation Service radar (recall: the initial involvement of Moore in Mrs. Hamadani's situation began 3 years prior to the events presented in "The Zadeh Scenario"). In reading the Zadeh narrative, it would actually be quite odd for any reader to think that this narrative - or any narrative for that matter - could provide such a total and complete documentation; no piece of writing, whether fiction or memoir can contain all such details.

Indeed, as Rasmussen discussed in some depth and Bishop also amplified (Rasmussen 2018; Bishop 2018), part of the device of "The Zadeh Scenario" is that, like any ethics consultation narrative which aims to provide some description of clinical ethics practice in those ways it is actually experienced, the Scenario is necessarily limited; it is a snapshot that is now outside of time even as it strives (whether successfully or not) to capture the sense and flow of time in Finder's work. The sense of time in the narrative, moreover, like much else in "The Zadeh Scenario," is the result of construction, i.e., the writing process. In the moment when Finder enters the elevator and Samir sees him, sees Finder's name badge and Finder catches a glance but doesn't make any particular reference to it while Samir is now focused by the fact that Finder's badge says that Finder is the Director of Ethics and hence Finder may be able to intervene and do something about what Samir perceives to be the peskiness of Moore - all of that unfolds in multiple moments, even layers, of time. For example, this represents a particular time as experienced by the Hamadani children over 3 years of their mother's illness while simultaneously representing the specific focus of the palpable sense of time experienced by Finder with Samir in the face-to-face confrontation on the plaza.

Far from a mere noting of certain obvious differences between experience and reporting on that experience, these details discussed above highlight a crucial starting point for any serious reading of "The Zadeh Scenario" and critical reflection on what it presents: "The Zadeh Scenario," like other such narratives that attempt to capture actual moments in the practice of clinical ethics consultation, is, as an example, a piece of fiction, a story, a matter of invention. By this we mean that it contains certain details but excludes a potentially infinite set of others. And akin to how many, if not most, of the details that are presented in the Scenario are presented intentionally, so too other details have been left out with similar intention. But perhaps more importantly, many details are also left out simply due to the limits of the narrative form itself. Another limitation of "The Zadeh Scenario," in other words, is not merely that it is a fragment; it is a story, a (hopefully) coherent narrative, a piece of composition by a specific author who initially set out to achieve something in that 
activity of writing about his experience. Moreover, experience, even if fragmentary - for instance, one's beginning is also always somewhere in the middle of one's, or others', experiences writ more broadly (a point Bishop briefly addressed) still remains different from reports about experience. Whether Finder included information in "The Zadeh Scenario" about where he was looking while in the elevator with Samir and Nadira, and whether he smelled stale food odor, and whether Samir and Nadira started to speak again once off the elevator and several yards in front of Finder as all three left the building, and any number of details about Finder's own perceptions, the environment, his thoughts, etc., in the midst of his actual experience were as they were; they occurred. And, sometimes, such occurrences turn out to be significant for the kinds of judgments one makes, for better or worse. We know that the ways others speak, appear, walk, and so forth can prompt prejudices, attractions, predispositions of various kinds that make subsequent interactions seem easier or more difficult. Similarly, in the midst of such noticing, tones of voice, word choice, fidgetiness, gestures, etc., of the other and oneself may alter how things subsequently unfold. The point here, quite simply, is that the concern for the presence or absence of details in stories is not merely about the integrity or trustworthiness of such stories; even if no story is to be told, these are the kinds of details that we routinely take into consideration when making judgments, whether it involves seemingly non-consequential judgments such as how loudly to speak (if there is some evidence of the other having difficulty hearing) to more substantive judgments (such as whether to offer one or two examples as part of an assessment of whether the other understands what one has just tried to explain). These considerations, as well as many more regarding clinical interactions, also point toward another kind of challenge associated with clinical ethics practice, namely, identifying what actually matters within those interactions with others, such that the things which may actually help become integrated into practice - and hence should be included and presented as part of peer review.

And all of the above leads to a final piece of important preliminary recognition that demands explicit notice: because stories such as "The Zadeh Scenario" (and similar efforts of clinical inquiry aimed toward representing some form of experiential truth) are constructed, created, designed, and limited, a central challenge must be addressed about how best to tell the experience of doing clinical ethics consultation in ways that accurately represent whatever might be taken as key ingredients of (and for) one's clinical ethics judgments. In other words, the methods that work best to re-present clinical activities and judgments may, even are likely to, obscure and alter key elements, including unique characteristics, actions, emotions, relationships and so on, that occurred in those moments of activity and judgment. Such are the limitations of writing.

Several of the peer reviews and commentaries acknowledged this point; we pay prolonged attention to it here because it is against this background that we must be vigilant. Indeed, the writing of this book has been inevitably framed by the kinds of inherent predispositions, prejudices, even unintentional deceptions - or if "deceptions" is too strong a term, the embedded conceits - of language. We are, therefore, keenly aware that the use of narrative devices and code words for the sake of re- 
telling and re-presenting events via "The Zadeh Scenario" and in each of the subsequent chapters, including this one, further inevitably shapes what readers are able to "see" within what is presented. And this point, we believe, is crucial for peer review writ large, for in that effort as well, the subtleties of experience transmitted through the language used to tell and to evaluate are altered, because what emerges in that focus, its themes, and transmission, becomes as much about the practice of writing or the practice of telling (about what we do when "doing" clinical ethics) as it is about the practice of clinical work. More importantly, this book was designed to demonstrate how the core questions which undergird peer review mentioned at the beginning of this chapter - What is the appropriate role (and expectations and goals) of clinical ethics consultation? What are the proper goods and practices associated with actually "doing" clinical ethics consultation, and hence serving as a clinical ethics consultant? What is the best way to capture this "doing" for the sake of peer learning? What is the most appropriate frame by which to engage in such learning, individually and as a field? - are to be, indeed, need to be engaged as part of the peer review process itself.

\section{What Exactly Does "The Zadeh Scenario" Attempt to Re-present?}

It is now necessary to turn our attention toward another crucial element of the Zadeh Project, namely, the necessity for distinguishing the goals, and associated models, for doing peer review - which will directly influence how clinical practice and moral experience are to be represented. As discussed in the Introduction, "The Zadeh Scenario" was not originally written for the sake of peer review, nor was it written in order to capture every facet of Finder's interaction with Mrs. Hamadani, her three children, and the various healthcare providers involved in her care. Nor, for that matter, was it written to capture the constituent elements of Finder's clinical judgments. Rather, it was written in an extensive moment of trying to make sense of an experience, and in so doing, the effort was to create coherent moments of that experience of being engaged in the actual activities and interactions encountered while serving as a clinical ethics consultant. It was only after it was written, also mentioned in the Introduction, that the idea of its value for exploring issues associated with peer review emerged since, unlike narratives written for the sake of promoting a particular view of one's practice or furthering a methodological argument about how ethics consultation ought to be performed, "The Zadeh Scenario" merely aimed to try to capture something of Finder's experience, warts and all if that's what it ended up showing. In this sense, its creation was primarily concerned with capturing something, and that something being from the past; it was not, in other words, written in the hopes of pre-configuring something for the sake of the future - such as concluding that what Finder did was done well. As such, the aim of writing "The Zadeh Scenario" was neither to glorify nor condemn Finder and his practice, but to 
draw attention to certain experiential demands of doing the work of an ethics consultant - and then to see if there was something to be learned by turning to that experiential account again, and with others bringing their own critical perspective.

Furthermore, whether Finder was able to achieve some recognition, or not, about what was vital to the interactions depicted in "The Zadeh Scenario," what has become clear throughout the Zadeh Project are the ways that such meanings - and even a family's grief - risk becoming appropriated into other narrative forms which unavoidably make those meanings into something else. With specific reference, then, to what matters morally, and to what is significant to the interpretation of the values and ethical bearing of those persons actually involved, the crux of the question is whether the "something else" made by ethics reports, or "ethics cases," or narratives about clinical ethics encounters adequately describes "something" of what it was and "something else" of what unfolded. For Finder, the initial impetus was whether "something else" was going on that may have been obscured, and yet was there and needed to be told.

As an example, consider Finder's last encounter with Mrs. Hamadani's children and Dr. Broukhim (Finder 2018, 37-42). If one primary activity for ethics consultants is to ensure that conversational formats are available and responsive to the actual circumstances, and that the necessary processes and interactions are attempted, in order to discover those values and standpoints that are relevant and meaningful for those people directly involved, then it would seem that Finder has brought forward a key moment, a decisive moment, in the moral conversations he portrays. Indeed, what unfolds is apparently quite clear regarding Samir's understanding of his mother's situation, the medical and family choices made so far, and what looms before him and his sisters regarding their mother's medical status such that he makes one final request not to talk about all of this anymore - and to talk about whatever needs to be discussed only with Dr. Broukhim going forward. All of those elements, as provided by Finder, would thus seem to accurately represent what it is like to actually be participating in that kind of conversation. And yet, as clear as that description may be, considerable ambiguity about the actual moral understanding of each individual still remains, as does a significant degree of uncertainty about the accuracy of the different appraisals being made, right then in the moments of that encounter which Finder attempts to capture over these pages. One sort of question then, is does this description accurately approximate what it is like to be in that kind of situation? If not, another question is: Do we need research studies with video ethnographies and verbatims? Furthermore, and more specific to our response here, there is this primary ethical question: In the context of what has been told, why wouldn't Samir Zadeh's requests be fitting and morally faithful to what has been going on?

The Zadeh Project as a whole is an expansion of that last paragraph: it has been designed to be, and aims to document, a process of discovery and the variety of ways that such discovery is relevant to clinical ethics practice, and more specifically, just how such discovery is engaged in by other clinical ethics consultants, especially when reviewing practice. And yet, as discussed by many of our collaborators already, writing for the sake of evaluation - using the typical set of understandings associated with "peer review" - is a different kind of activity than writing for the sake of reporting or for the sake of discovery. If the aim of peer review is and 
should be evaluation - and even further, to establish (or not) an individual's satisfying some kind of professional requirement (such as may be part, for example, of a professional credentialing process) - then how an ethics consultation is represented in a written format may be quite different from what is found in "The Zadeh Scenario." The same holds for "case write-ups" that serve as part of the reporting structure within an institutional accountability framework (such as the VA's IntegratedEthics' CASES model) since the aim of that kind of endeavor differs as well from either the aim of discovery or the aim of establishing professional standing. This is a crucial point to note because it begs a critical question central to the Zadeh Project as a whole: is "The Zadeh Scenario" sufficient for probing questions regarding clinical ethics consultation peer review?

How to answer that question depends upon what, exactly, "peer review" is said to entail - a question which itself brings to light that "peer review" may be understood quite variably; examples include: evaluating an individual's performance against some established set of standards for the sake of admittance into or dismissal from a group (e.g., a professional society, a institutional staff, a practice group); determining suitability for sharing one work within a professional community (as occurs with manuscript review or presentation proposal review for professional meetings); establishing merit for the sake of having projects funded (expert panel reviews, for instance, by granting agencies); learning from an individual how he or she practices; or serving as an occasion to reflect more extensively on the practice in which peers share a commitment. While not meant to be an exhaustive or definitive list, the point is that "peer review" may refer to a variety of practices, each with potentially different aims, criteria for evaluation, format demands, etc., some of which may themselves thwart or undercut the legitimacy of the other possible aims, criteria, formats, etc. These sort of tensions are actually demonstrated by the ways that the very form and style of "The Zadeh Scenario" serve as points for critique by several authors in Parts Two, Three, and Four.

Perhaps more importantly, along with assumptions regarding the purpose of peer review and the acceptable forms for providing accounts of clinical ethics practice, there is also a wide array of substantive commitments regarding clinical ethics practice within the field of clinical ethics generally; this is wonderfully, and most explicitly, demonstrated by the chapters constituting Part Three. Demonstration of this array is also found within both "The Zadeh Scenario" and the various replies and commentaries of our collaborators; this array may be captured, and briefly explored, under the heading of two simple questions: (1) Where is Mrs. Hamadani in all this? and (2) Where are the "ethics"?

\section{Where Is Mrs. Hamadani?}

Clinical medicine has as its central focus the patient who presents him- or herself in need of help; the moral obligation to provide care thus begins with that very request for help (Pellegrino and Thomasma 1981). This understanding of the source of 
medicine's obligation, and thus the moral grounding of clinical practice, is ancient. Perhaps not surprisingly, a similar kind of primacy is given to the patient in discussions of the moral obligations associated with clinical ethics consultation; it is almost a kind of unspoken cardinal rule that the primary source of ethical concern within any given clinical context is patient-centric. However, just as the nature of clinical contexts are inherently dynamic due in part to the diversity of people interacting with one another from within many different roles (of which the patient is but one individual occupying but one role), the source of ethical concern in a given clinical situation may be similarly varied and diverse (Zaner 1988) - and, in fact, may primarily not be grounded in matters associated with the patient per se. Think, for instance, of situations in which different providers understand their responsibility toward a shared patient differently such that questions of intra- and interprofessional obligations are at issue. Or consider when an individual provider encounters internal moral disruption due to competing commitments - perhaps due to institutional versus professional obligations, individual versus group commitments, local versus national standards of practice, and so on - that might temporarily inhibit that individual from acting, or from acting well.

If part of the aim of clinical ethics consultation is to identify and clarify what is at stake in a given clinical situation (a point made by several of the contributors to this volume and one which we have argued in numerous publications [Bliton and Finder 1999, 2002, 2010; Finder and Bliton 2008, 2011]), then it follows that what may be demanding of attention, in that effort to discover what's going on, may not directly concern or be immediately about the patient at all. Indeed, if, for example, the locus of ethical concern is the felt sense of responsibility of a son or daughter of a patient, especially when the patient lacks the ability to interact with care providers and hence it is to the patient's children to whom care providers turn for input when crucial decisions need to be made regarding the patient's care, then so too must the ethics consultant direct attention to these individuals. Clarifying their sense of responsibility would thus be of central import for the ethics consultant. As such, it is not necessarily the patient per se who is most important even if the concern for the son's or daughter's sense of responsibility is due to something concerning the patient; in seeking to understand what matters to that son or daughter, it is him or her that is of central concern in the actual engagement of ethics consultation. Sometimes, then, it is the family, or the nurses, or the physicians, or others, to whom ethics consultants must direct their care and attention - and hence it is not merely or primarily the individual who lies in the bed that requires that focus.

Consider now what is displayed in "The Zadeh Scenario" and a recurring criticism of Finder in the subsequent commentaries: Mrs. Hamadani is peripheral, not central. More specifically, while Mrs. Hamadani's situation is the center around which events in general revolve, as Finder tells it, he seemingly did little (or perhaps even nothing according to some of our collaborators) to uncover directly Mrs. Hamadani's voice during his involvement with her family. Instead, as the critiques of Finder's practice maintain, the primary focus of his attention, and the primary voice to which he seemingly listens, is that of Mrs. Hamadani's family, and in particular, her son, Samir. Mrs. Hamadani appears to be essentially absent from the 
ethics consultation - a point that could have been amplified by our collaborators (we are surprised that none mentioned this so directly) by noting the very title of the narrative: it is "The Zadeh Scenario" - and hence not "The Hamadani Scenario."

The critical question to be asked, however, is whether Mrs. Hamadani's voice, if present or absent, is the right frame for critiquing what Finder presents in "The Zadeh Scenario"? Or, put slightly differently, why not focus on Samir? To be sure, the emphasis on Samir and the concerns he highlights are themselves framed by Mrs. Hamadani who, at the point that Samir confronted Finder outside of the hospital's entrance, is critically ill in the ICU, and the picture painted of Mrs. Hamadaniby her children, by her physicians, by Finder's colleague Moore - throughout the scenario is not one of an engaged, awake, alert patient. But imagine that things were different, that in the narrative Finder reported that Mrs. Hamadani was fully capacitated, was fully engaged in participating in decision-making about her care; how would that be relevant to Finder's engagement with Samir? With Nadira and Farzana? With Broukhim? With Moore? And, within a concern for practice, what is Finder actually to do, in the sense of actual tasks and activities as occur within institutional settings such as a hospital once Samir stops him and begins his disquisition?

Continuing with this imaginative theme, the answer, if one is to root the answer in what institutional life allows - including the institutional dimensions of clinical ethics both as locally practiced and professionally promoted (by, for instance, ASBH via the Core Competencies and corresponding Education Guide publications [ASBH 2011, 2015, respectively]) - is that it depends. The details of the situation make a difference, and with just a bit more imagination, we can fashion scenarios in which the fact of Mrs. Hamadani's capacity and her having a voice in her plan of care may have everything to do with the ethical dimension of how any of these involved individuals may be experiencing their felt sense of responsibility - or very little to do with the sense of responsibility. For instance, if Mrs. Hamadani's children are struggling to honor their mother who, they report, is being explicitly clear that they not interfere with what she has decided is best for herself - even to the point that she refuses to talk with social workers, chaplains, or others who may be interested in trying to help foster better relations between her and her children as she is now coming more rapidly to the end of her life - what would be the rationale to assert that the ethics consultant must, nonetheless, engage with Mrs. Hamadani even when she's explicitly requested no such engagement (such being duly documented in her medical record)? Or had Finder discovered, in the aftermath of Samir's initial request to keep Moore away from this situation, that Broukhim was struggling with his obligation toward Mrs. Hamadani but found his interactions with Moore to provide great moral support - not in the sense of "emotional support" (which several of our collaborators present as important but somehow diminished in import in comparison to "ethics") but in the sense of allowing for the examination and affirmation of key facets of his obligations as a care provider, i.e., Moore helped Broukhim better understand and appreciate the ethical dimensions of medical responsibility for what possible reason would it be necessary to give voice to Mrs. Hamadani's concerns? The only plausible answer would be if Mrs. Hamadani's concerns were 
material for Dr. Broukhim's concerns, which could be the case but need not be the case. And if not the case, then no need to bring Mrs. Hamadani's voice into that context except insofar as to clarify what matters for Broukhim. This raises two crucial issues.

First, it seems that the argument for bringing Mrs. Hamadani's voice into this context is grounded in the presumption that clinical ethics, like medicine, must be patient-centric. If so, then this effort to hear from Mrs. Hamadani as part of the effort to lend moral support to Dr. Broukhim reflects a kind of contradiction since her input is sought for the sake of helping Brouhkim (and hence is not, per se, a patient-centric effort). Be that as it may, there is a second problem: to seek Mrs. Hamadani's input presumes a kind of positivity, namely that Mrs. Hamadani will not be harmed by seeking her input. But Finder does not yet know, after he has spoken with Samir and Nadira, whether Mrs. Hamadani's contribution will have a positive, negative, or neutral effect on her. Indeed, at the beginning, Finder lacks any context-specific criteria for even evaluating whether such contribution will be positive, negative, or neutral. To begin with the assertion, nonetheless, that Finder must give voice to Mrs. Hamadani thus seems to bring into the context a set of values or commitments that are grounded outside of this situation. Perhaps the response would be that while it is not clear at the beginning, it will become clear later on, as Finder learns more about the situation, Mrs. Hamadani, and so forth. But here too arises that possibility that seeking Mrs. Hamadani's input may turn out not to be necessary, and perhaps, even harmful.

These imaginative exercises are in no way merely academic. Rather, they reflect some elements of what is at stake in actually moving beyond the reception of a request for clinical ethics consultation into taking actual and practical steps forward into an unfolding process. A number of our collaborators make explicit appeal to the fact that clinical ethics practices are contextually bound and hence clinical ethics practitioners must be able to respond, and hence will be held accountable for such responsiveness, to what is actually going on. What "is actually going on," the ways to recognize and describe that, becomes the focal issue - and more importantly, the moral awareness that with any particular step forward into that unfolding future, the steps chosen are not free of value, free of commitment, free of implication for what is held as worthwhile and what, conversely, may be disregarded or deemed to be not as important or valuable or worthwhile.

With that being said, the more important point to address at this juncture of the unfolding which has occurred over the past 175 or so pages is that the assumption of patients having a privileged placement in the context of clinical ethics consultation may become problematic for evaluating the work that an ethics consultant performs as part of ethics consultation. Indeed, even if Mrs. Hamadani was fully capacitated and wanted to be fully involved in the decision-making associated with her healthcare, the apparent starting point for Finder in which he becomes more directly involved with Mrs. Hamadani's situation is Samir's stopping him and asking for his help. So, as one beginning point, Finder must respond to Samir and what he presents. What comes next will depend on what occurs there, then, at that beginning point. 
In that respect, one of the factual points becomes about the "here and now" of the Scenario, that it was not Finder who chose to begin with Samir; Samir chose to approach Finder. In that moment of beginning, and going forward as well, how to understand and evaluate what Samir subsequently presents to Finder, and how to integrate that into what Finder might subsequently learn about Mrs. Hamadani and her situation, becomes part of Finder's task as ethics consultant. Finder's work as an ethics consultant thus includes being able to evaluate what is presented by Mrs. Hamadani's family. And returning for the moment to what is presented by and found within "The Zadeh Scenario," this evaluation for which Finder is responsible is to be done in the context in which Mrs. Hamadani was critically ill, in the ICU, and, based on the available medical reports which Finder reports in the Scenario, dying. It is not that being in the ICU and being critically ill and dying negate a patient from having a voice; it is that in tertiary care hospitals having ICUs, most of the patients in the ICU have no voice except as available through their representatives (family, formal Agents, etc.), and hence it is toward those others that ethics consultants must turn.

And this highlights a critical practice element for doing clinical ethics consultation: in actually turning attention toward these other individuals, i.e., Mrs. Hamadani's children, Finder must respond to whatever it is that they present even if, it turns out, what they state is not likely or even accurately reflective of what this patient, Mrs. Hamadani, would speak if capable. Especially at the beginning, Finder does not know which way it will work out and so must take as legitimate what these others present (even if also maintaining a kind of skepticism in order to assess that legitimacy). In this sense, it may be said that Finder must be responsively responsive when responding to what is presented to him in any given clinical ethics moment (to play off the notion, in the immediately preceding chapter, of "responsive evaluation" [Widdershoven et al. 2018: 199-200]).

As such, at least one crucial reflective point about clinical ethics consultation practice to highlight here is that once called into a situation, the ethics consultant must be prepared to address the concerns of the other individuals who accompany patients. And, such concerns are to be addressed with full intentionality and with utmost care and concern since what is presented may be an accurate representation of what the patient would speak if capable - but may not be. Furthermore, if the patient is owed some form of initial respect, so too are those others who present themselves as representing the patient even if, it subsequently turns out, what they present does not represent the patient. Highlighted in this way, a core ethical point about clinical ethics practice becomes evident: part of the practice is to be prepared to take into careful consideration what a family presents, and hence not only the patient (as the body in the bed and hence the focus of medical attention).

An obvious point perhaps, one we hope generates little disagreement. What is noteworthy, on the other hand, is that the details associated with the depth and extent of such careful attention, of how this is actually done and how doing so is experienced within clinical ethics practice, receives little explicit attention in the clinical ethics literature. This dearth of attention is, in fact, part of what motivated the Zadeh Project initially. More importantly for the actual practice of clinical ethics consultation, it is within the context of such moments of needing to learn from those 
with whom one is now interacting - especially when they are individuals with whom one has had no prior relation and hence are, for the most part, strangers - that this very practical questions gains force: "How best does one engage in the process of discovering what matters in what is going on?"

When discussing a book or a journal article or even a narrative fragment such as "The Zadeh Scenario," the form of questioning, and hence of discovering what is meant or what serves as a central point, is typically direct; one can ask simply and plainly, "what does this paragraph (or sentence or word) mean and how does it relate to whatever else the author has written?" And, this may be asked directly in part because that which is being questioned is itself partially contained between both what has been written (and hence read) so far and what is yet to be read but nonetheless still also already written - and hence already determined (in the sense that subsequent paragraphs, sentences, even words are already written, already presented, already there, which is what allows for direct examination). The same, however, cannot be said of conversations which occur in the midst of clinical ethics practice (hence another element of ambiguity associated with "The Zadeh Scenario," and with any after-the-fact "case report" that re-presents what occurred at some prior moment; those words, i.e., the words of the case report, and hence, for example, of "The Zadeh Scenario," are now set even as what they re-present was, at the time, not set but unfolding). Conversations, in the ways they actually occur between people, are full of uncertainties, ambiguities, and all sort of unknowns - including what may turn out to be informational mis-directions or even flat-out nonsense.

In the face of the actual uncertainty of what it is that one is encountering in the midst of having conversations as part of clinical ethics consultation, it may be suggested that such clinical interaction requires indirection, because being direct may not only not be possible (meaning is still developing, still unfolding, still being formed) but runs the serious risk of over-determining the meaning of what is unfolding in such conversations. Accordingly, clinical ethics practice has need for a kind of covert operative element, that is, something that aids in scoping out what actually matters to those individuals with whom the ethics consultant speaks. Moreover, this must occur in a manner that does not force interpretation before even initial meaning is allowed to unfurl. Hence, even the manner in which a question is asked, or a statement is acknowledged, must be done with care; the actual words chosen, and the inflection utilized when speaking those words, can make a difference in how what is said is understood by the other with whom one is speaking. The experiential dimension of "doing" clinical ethics is thus no mere secondary consideration.

Accordingly, consider how all of the above is actually performed. In "The Zadeh Scenario," some of this is demonstrated by how and where Finder meets with his various interlocutors. For instance, he goes and meets with Mrs. Hamadani's two daughters, Farzana and Nadira, in Mrs. Hamadani's ICU room. Hynds is critical of this meeting insofar it does not include all potential stakeholders, including medical authorities who may address technical questions or concerns that may arise (Hynds $2018,90-1)$. On the one hand, this is a legitimate concern since the possibility is clearly present that Farzana or Nadira may ask questions about any number of aspects associated with Mrs. Hamadani's care (including insurance issues, dietary 
questions, and so forth; it is not merely medical expertise that is absent from the room when only Finder is there) for which Finder is unprepared, and professionally unable, to address. But the possibility of such matters arising without the needed experts being present points toward the need for the ethics consultant to know, and abide by, the limits and bounds - and hence responsibilities - of ethics consultation as practiced within the particular context. The fact of uncertainty, in other words, does not demand an avoidance of possibility. More importantly, and thus on the other hand, this concern fails to appreciate how the contexts of conversation both shapes and limits the content of such conversation. Talking with a patient's family within the confines of their domain in the hospital, i.e., the patient's room, may provide them greater comfort and hence trust as compared to bringing them to some other room for a "family meeting," the connotations of which may prevent them from speaking openly and honestly about whatever it is that they, for themselves, hold to be most significant and worthwhile.

The point here is not that ethics consultants should never meet in rooms other than patient rooms, or that ethics consultants should or should not talk with patients and their families independently of other healthcare providers. Rather, it is to raise for inspection core questions about how one might go about actually learning from patients and families about what matters most to them regarding the situations in which they find themselves as well as in some or another future into which they are headed. And in this light, Finder's going into Mrs. Hamadani's room to talk with Farzana and Nadira highlights something else: developing trust with others who are mostly strangers is as much a practical dimension of clinical ethics practice as other more typically identified skill and knowledge sets (e.g., as outlined in ASBH's Core Competencies document). Clinical ethics consultation thus demands a kind of deliberateness in clinical conversation, especially with patients or families, that is quite different from other kinds of engagement in which ethics consultants might participate (for instance, with ethics colleagues or administrators or members of the media). After all, whatever level of trust that may be embedded within the role of "ethics consultation" within the particular institutional context in which ethics consultation is practiced, or within the role of "ethics consultant" for those who fulfill the institutional role of ethics consultation, the trustworthiness of those who fulfill the role needs to be newly established for each new ethics consultation, and possibly even for each encounter within a given consultation - and this develops mostly by how and when and where those individuals occupying that role engage with others.

In summary then, rather than asking, "Where is Mrs. Hamadani?" the questions to ask are, "Whose voice should be given attention, and why?" and "How should the various voices that are present in the situation be balanced?" And equally important, "By what means should Finder have gone about discovering what matters most for each of these stakeholders given the actual dynamics of the situation as they became known?" As much as following protocols and abiding by policies, engagement in ethics consultation in the effort to answer these questions demands responding to accidental and unforeseen (and unforeseeable) factors; as Agich emphasizes in his commentary, clinical ethics consultation is a practice, and not just a body of knowl- 
edge or a set of skills (Agich 2018, 142-4). "Being responsible" in the role of "ethics consultant" is therefore not reducible to "being responsible" in the role of "ethics consultation" since the latter addresses institutional demands whereas the former focuses upon the enactment of those institutional demands within the real and dynamic contexts of actual clinical engagement with particular patients, families, clinician colleagues, etc. To "do" or "perform" or "engage in" clinical ethics consultation is thus (in part) to be continually refining and adjusting (what is being done, understood, developed, etc.) in response to what is encountered in the specific clinical situation - in which "the specific clinical situation" references both this particular clinical situation (as distinct from other clinical situation revolving around other patients) and this specific moment in this particular clinical situation. To respond as such, i.e., to refine and adjust what one is doing in response to what one is encountering (and to do so in real time), is another way of saying that ethics consultants must be responsively responsive to what they encounter.

\section{Where Is the "Ethics"?}

Responding responsively to what is actually encountered as part of clinical practice serves as an important dimension of the ethical grounds for "responsibility" in clinical ethics practice. This is no mere analytic assertion, however; the idea of responding responsively highlights the fact that even those taken for granted commitments and understandings which frame and define clinical ethics consultation itself are, potentially, available for questionings or interrogation as part of clinical ethics consultation. This is especially so if what emerges as significant for those individuals with whom the ethics consultant interacts raises questions regarding such commitments and understandings.

A key question, then, is what should serve as the appropriate form of analysis regarding Finder's engagement with the sort of complexity as is found within the specific situation presented in "The Zadeh Scenario"? This question is itself complex and multi-layered - and this is independent of the important concern addressed by both Rasmussen and Bishop that peer reviewing Finder is wholly dependent upon how Finder is presented via the Scenario narrative, i.e., if Finder, the author, has done a poor job of re-presenting his actions in the "The Zadeh Scenario," then whatever is said about "Finder" the ethics consultant within the narrative is severely limited (Rasmussen 2018; Bishop 2018). Granting that Finder's depiction of his practice, even if fragmentary, is nonetheless accurate, the question of appropriate ethical analysis has at least three layers.

First, with Samir's turning and stopping Finder outside the hospital doors, Finder immediately becomes a direct participant in a situation about which, at the moment of initial engagement, he knows nothing and he is, in a manner of speaking, a complete stranger, an outsider, someone who has suddenly crossed the border into a new territory, namely, the life of Mrs. Hamadani and her children. In that initial moment, the immediate question he faces is not merely how to take in and maneuver through 
what is now actively unfolding before him as Samir tells his tale but whether some sort of response beyond an administrative-role-based one is warranted. Finder, in other words, is at a kind of ethical juncture where he must attempt to make sense of, and evaluate, the various kinds and degrees of commitments, values, and beliefs regarding what Samir seemingly holds to be worthwhile as such are expressed by what Samir is speaking. A similar kind of evaluative effort will, of course, likely be repeated as Finder becomes more involved in the situation and thus encounters expressions of, for example, notions of felt responsibility (professional, institutional, personal) among the many individuals involved in caring for Mrs. Hamadani and interacting with her children. There will also be expressions of familial obligation bound-up in what Samir, Nadira, and Farzana tell him as well as in their understanding of love for their parents and for each other. At various junctures of encounter, Finder must assess, and possibly re-assess so as to determine what to do next.

At issue, in the moments of actual consultation activities, then, are practical considerations such as what responsibility might mean: for instance, to Samir, to Dr. Broukhim, to other providers involved in the care of Mrs. Hamadani and in the support of her children, and so on. The probing of any one of these individual's selfunderstanding of his or her responsibility will require some form of ethical evaluation on Finder's part as he "takes in" what each offers (whether directly or indirectly) about his or her understanding of responsibility.

In that exploration, there is then a second question about ethical analysis, namely, as Finder engages the issue of the meaning, for example, for Samir of Samir's responsibility, what kind of ethical frame should Finder utilize to assess the responsibility Finder himself bears in assessing Samir's responsibility? This is a potent question since how Finder understands his responsibility will shape how he engages Samir, and draws from Samir, Samir's own understanding of his (Samir's) own responsibility and that of Finder in turn; this is what it means, in part, for Finder to be "responsively responsive" in this situation. And whatever the frame for exploring and developing understanding of Samir's commitments, beliefs, values, and so on, Finder must also determine which to use with Broukhim, with Moore, with the others; these may be the same or these may differ - but whether same or different, if the goal of Finder's interaction with these many individuals is to discover what actually matters to them such that each sees this or that option, action, decision as better or worse, Finder's choices here are no light matter. A miscalculation in understanding runs the risk of altering the possibility of further exploring with these other individuals what actually is at stake for them, information that is necessary (even if not sufficient) for Finder's ability to help in the situation.

And with all that said, there is at least, then, a third layer of ethical assessment, namely, that which is to be utilized by Finder's peer reviewers - especially if the presentation Finder provides (via "The Zadeh Scenario," for instance) is divergent from typical norms of "ethics consultation" (for instance, that a patient's voice is paramount). For Finder's peer reviewers, to not take up this third layer of assessment (i.e., their own frame for evaluating Finder's practice) as part of their engagement with the narrative and then their evaluation of Finder runs the serious 
risk of misunderstanding what Finder may be trying to present in his narrative akin to Finder risking misunderstanding, for instance, what Samir presents in Samir's presentation (including his initial confrontation with Finder outside the hospital doors or in the meeting in which he, his sisters, Finder, and Broukhim had which is recounted near the narrative's end). And so a fourth layer emerges as well: what kind of ethical analysis is at stake not merely for Finder's peer reviewers but for the process of peer review itself?

Given the above, it is curious to note that through-out Parts Two, Three, and Four, the idea that "The Zadeh Scenario" lacks any evidence of ethical analysis, that Finder offers no account of "ethics" in his narrative, is repeated. This claim, however, may be said to be more a reflection of presumptions by our collaborators about what counts as "ethical analysis" - and hence the subject of the third layer described above - than what Finder presents or does. Indeed, it may be argued that the entirety of the Scenario is an exemplification - as opposed to a didactic description - of at least the first two layers of ethical concern described above. And taken together with the critiques lobbied against Finder, this entire book is explicitly, but as an indirection, raising the question of the fourth layer, as a form of critical engagement. So while we agree that "ethics" as typically discussed in didactic texts is nowhere to be found in "The Zadeh Scenario," it is, we believe, everywhere evident in the story told, in the responses to that story, and in the subsequent responses to the responses. Once again, therefore, we return to the notion of unfolding and the idea that meaning and responsibility in the actual practice of clinical ethics consultation, as experienced by those who serve in the role of clinical ethics consultants, is to be, at least in part, discovered through the process of engagement with others.

\section{Drawing to a Close: Learning for the Sake of Improving Practice}

In the opening paragraph of this chapter we noted that underneath the core questions and themes that emerged in Parts Two, Three, and Four is a more fundamental and crucial question facing those who engage in clinical ethics consultation practice, namely, what is the most appropriate frame by which to share with and learn from each other regarding the actual performances as clinical ethics consultants - and then, by extension, how best to engage in such sharing and learning not merely individually (as might occur among immediate colleagues within a given clinical ethics consultation service) but also as a field? On the one hand, the very structure of this book explicitly reveals much about what we, the collective authors of this book, take to be necessary in that effort: one must be willing and able to attempt to capture an account of one's clinical ethics practice experience. One must be further willing to put such representation of one's performance before others for the sake of discovering what cannot be discovered on one's own, i.e., being committed to collaboration as key for developing self-understanding. One must also be willing to 
collaborate with others from a breadth of backgrounds and perspectives regarding the practice of clinical ethics - and thereby be willing to accept that diversity in clinical ethics practice should be sought, not eliminated. In addition, that experience, accounting for experience, critiquing experience and critiquing accounts of experience are neither interchangeable nor reducible to each other nor mutually exclusive. And finally, we take as necessary that the ethical dimensions of clinical practice, clinical experience, clinical reporting, and the review of each are grounded in such experience, practice, and accounting - and hence not originating from what may be outside or beyond the limits of the clinical.

With all that being said, on the other hand, the aim of the Zadeh Project, beginning back in at least 2009 when the initial idea of putting together that first panel in which the Zadeh narrative was presented for colleagues to then critique, has also always been to raise questions for the sake of challenging whatever presumptions and pre-conceptions we, and our collaborators, may bring into the Project; this includes presumptions about not merely whatever may be more directly revealed (or hidden) in the Zadeh narrative itself but also as regards clinical ethics practice more generally as well as clinical ethics method, clinical ethics training, and efforts to professionalize the clinical ethics field. The structure and content of this book, therefore, has been designed to equally challenge and promote - and in the process, offer an account of that practice. Rather than write a book that offers didactic direction regarding the process and role of peer review and peer learning as pertains to clinical ethics practice, we have sought to display it and to leave for you, the reader, the ensuing questions not merely to ponder, but to incorporate in whatever account of peer review you (and we) might subsequently build, locally for our own individual clinical ethics consultation services and as a field.

As such, there is another set of fundamentally ethical considerations with which we are committed - but which we are as yet unwilling to challenge - and that is the centrality of affiliation and trust as central grounds upon which clinical ethics consultation practice must rest. Through-out this book, the themes of affiliation and trust have been present, whether it is within the relational dynamic of Finder and Moore, Finder and Broukhim, Finder and Samir Zadeh, Samir and Farzana and Nadira, Broukhim and Mrs. Hamadani's children, Finder and all five authors in Part Two, those authors and the authors of Parts Three and Four, or all of us who have collaborated in this book and you the reader. At each level, there is something shared, something trusted, something ingredient to clinical ethics practice.

Whatever else may be found within "The Zadeh Scenario," one thing that stands out is an expression of multiples forms of obligation that texture and shape clinical encounters. There are obligations of healthcare providers: to patients, to the family members who accompany their patients, to clinical colleagues, to their institution, to their profession. There are obligations of family members: to their loved one the patient, to each other as family and those who care about the patient (even if not directly providing care to that patient), to those who provide care to their loved one the patient, to their community that extends beyond family and patient in which their lives have been and will continue to be lived. And there are obligations of 
professions, of institutions, and of communities in which patient, family, and healthcare providers may interact beyond the healthcare context that also are brought forth into clinical contexts, sometimes intentionally, sometime explicitly, oftentimes only by presumption. In many instances, those presumptions are difficult to find, difficult to understand, difficult to manage because, for the most part, most who are brought together by a particular patient's situation - patient and family, on the one hand, and healthcare providers on the other - are strangers in each others' worlds, which itself raises questions about responsibility each may bear in the face of that shear, and mundane, fact. Whatever else clinical ethics consultation may, or must, address, this fact cannot be overlooked if the aim of clinical ethics, even nominally, is to address what may serve as the source of ethical tensions, conflicts, and disruptions revolving around a patient's care.

And this brings us full circle to the issue of fragment, because any form of giving an account is fragmentary - and "fragmentary" as defined by any number of political, professional, institutional, cultural, etc., criteria in light of which the issue of understanding and evaluation occurs. And this holds true not merely within the context of discrete clinical interactions but also for any form of peer-to-peer engagement, most especially when what is at issue is institutional/professional understanding and evaluation. So, in the end, the question raised by several of our collaborators regarding "The Zadeh Scenario," namely, does it present an "ethics" consultation at all, may be the penultimate question to consider. In ways it is and in ways it is not. It is surely an example of clinical ethics support, and there was awareness and alertness to many of the aforementioned factors of affiliation and trust in the activity of actually staying in conversation in and with the situation, which represents a kind of inquiry that is ingredient and essential to clinical ethics consultation. To be sure, again as various collaborators have highlighted, within the scenario there was not mention of any formal analysis; the primary focus was to support the family and physicians in what was unfolding in the care of this patient, Mrs. Hamadani, as she lay dying. At the deepest layer, then, is the question of what ethics "consultation" is to mean when the kind of engagement revolves around the moral dimensions of patients care, dimensions in which ethical analysis may be possible (from a distance) but not necessarily asked for or fitting in the moments of engagement.

At stake is therefore the very question of ethics and of consultation in the meaning and commitments associated with clinical ethics consultation. Peer review thus becomes an occasion not merely of vetting who can pass as an ethics consultant worthy of that moniker but for critical engagement within the field regarding the question of ethics and of consultation. Peer review is, in other words, yet another means for peer learning about what we in the field hold to be of fundamental value. But it is not enough merely to state those values; they must be enacted in the very "doing" that is clinical ethics practice. And similarly, they are to be found in what we present to, and seek from, our peers.

Peer review, in the context of peer education, rests upon a commitment to model - and demands engagement with - what is most worthwhile for the practice and the field of clinical ethics. This book has attempted to lay out some of the 
commitments that we, the collective authors of this book, share - and question including the need to provide accounts, seek critique and guidance from peers, and to consider the implications of such critiques. Such efforts, of course, are in some sense, never completed as the very engagement will, inevitably, lead to more questions. But that is part of the goal, part of what is sought, for in the emergence of new questions arises the opportunity to learn, to reform, to move (hopefully) forward into something improved; whether it is an improvement, of course, remains to be seen.

This chapter began with the acknowledgement that foretold in that first encounter Finder had with Samir Zadeh are many if not most of the core questions and themes that subsequently emerged in the ensuing layers of review and commentary that constitute Parts Two, Three, and Four. Now at the end of the chapter, and at the conclusion of the Zadeh Project (as it is captured by the pages of this book), we here return to those core questions, only now as transformed through a process of recognition, identification, appraisal, clarification, and evaluation:

How might one be responsible in clinical ethics practice?

How might one be responsible as a clinical ethics consultant?

How might one be responsible for the practice of clinical ethics consultation?

How might one be responsible to the field of clinical ethics?

We leave these questions with you, the reader, in the hopes that you will take them up and come to discover something of significance for not merely what you do if you "do" clinical ethics consultation, but how, and why, to engage in peer learning and peer review - for yourself, for your immediately colleagues, for the broader set of colleagues with whom you regularly interact while fulfilling whatever the local institutional expectations of "ethics consultation" may be, for administrators who need to know why what you do is worth supporting, and for the field as it continues to develop into whatever it is that "ethics consultation" will come to mean going forward. We have attempted to model a way of doing so, one that entails providing imaginative variations of experience, reflection, response, and exploration. The task is now yours.

\section{References}

Agich GJ (2018) Narrative and method in ethics consultation. In: Finder SG, Bliton MJ (eds) Peer review, peer education, and modeling in the practice of clinical ethics consultation: the Zadeh project. Springer, Cham, pp 139-150

American Society for Bioethics and Humanities (2015) Improving competencies in clinical ethics consultation: an education guide, 2nd edn. American Society for Bioethics and Humanities, Glenview

Bishop J (2018) Doing well or doing good in ethics consultation. In: Finder SG, Bliton MJ (eds) Peer review, peer education, and modeling in the practice of clinical ethics consultation: the Zadeh project. Springer, Cham, pp 179-192 
Bliton MJ, Finder SG (2002) Traversing boundaries: clinical ethics, moral experience, and the withdrawal of life supports. Theor Med Bioeth 23(3):233-258

Bliton MJ, Finder SG (1999) Strange, but not stranger: the peculiar visage of philosophy in clinical ethics consultation. Hum Stud 22(1):68-97

Bliton MJ, Finder SG. 2010. A Brief Reflection on the Experience of Responsibility in Ethics Consultation. Formosan J Med Humanit 11(1\&2): 93-102

Finder SG (2018) The Zadeh scenario. In: Finder SG, Bilton MJ (eds) Peer review, peer education, and modeling in the practice of clinical ethics consultation: the Zadeh project. Springer, Cham, pp 21-42

Finder SG, Bliton MJ (2008) Responsibility in actual practice: consent and participation in clinical ethics consultation. In: Hester M (ed) Ethics by committee: a textbook on consultation, organization, and education. Rowman \& Littlefield, Lantham, pp 79-106

Finder SG, Bliton MJ (2011) Responsibility after the apparent end: 'following-up' in clinical ethics consultation. Bioethics 25(7):413-424

Hynds J (2018) Ethics consultation, professional praxis, and what it means to be a "consultant". In: Finder SG, Bliton MJ (eds) Peer review, peer education, and modeling in the practice of clinical ethics consultation: the Zadeh project. Springer, Cham, pp 85-97

Pellegrino ED, Thomasma DC (1981) A philosophical basis of medical practice: toward a philosophy and ethic of the healing professions. Oxford University Press, New York

Rasmussen L (2018) Standardizing the case narrative. In: Finder SG, Bliton MJ (eds) Peer review, peer education, and modeling in the practice of clinical ethics consultation: the Zadeh project. Springer, Cham, pp 151-160

Widdershoven G, Molewijk B, Metselaar S (2018) Peer review and beyond: towards a dialogical approach of quality in ethics support. In: Finder SG, Bliton MJ (eds) Peer review, peer education, and modeling in the practice of clinical ethics consultation: the Zadeh project. Springer, Cham, pp 193-203

Zaner RM (1988) Ethics and the clinical encounter. Prentice-Hall, Inc., Englewood Cliffs (Reprinted in 2002 by Academic Renewal Press)

Open Access This chapter is licensed under the terms of the Creative Commons Attribution 4.0 International License (http://creativecommons.org/licenses/by/4.0/), which permits use, sharing, adaptation, distribution and reproduction in any medium or format, as long as you give appropriate credit to the original author(s) and the source, provide a link to the Creative Commons license and indicate if changes were made.

The images or other third party material in this chapter are included in the chapter's Creative Commons license, unless indicated otherwise in a credit line to the material. If material is not included in the chapter's Creative Commons license and your intended use is not permitted by statutory regulation or exceeds the permitted use, you will need to obtain permission directly from the copyright holder.

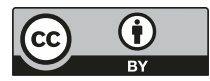

